\title{
Measures of fine motor skills in people with tremor disorders: appraisal and interpretation
}

\author{
Kathleen E. Norman ${ }^{1,2 *}$ and Martin E. Héroux ${ }^{3}$ \\ 1 School of Rehabilitation Therapy, Queen's University, Kingston, ON, Canada \\ ${ }^{2}$ Centre for Neuroscience Studies, Queen's University, Kingston, ON, Canada \\ ${ }^{3}$ Neuroscience Research Australia, Sydney, NSW, Australia
}

Edited by:

Tim Vanbellingen, University Hospital Bern, Switzerland

\section{Reviewed by:}

Maria Stamelou, University College London, UK

Katya Kotschet, St. Vincent's Hospital, Australia

\section{*Correspondence}

Kathleen E. Norman, School of Rehabilitation Therapy, Queen's University, L.D. Acton Building, Kingston, ON K7L 3N6, Canada. e-mail:kn4@queensu.ca
People with Parkinson's disease, essential tremor, or other movement disorders involving tremor have changes in fine motor skills that are among the hallmarks of these diseases. Numerous measurement tools have been created and other methods devised to measure such changes in fine motor skills. Measurement tools may focus on specific features - e.g., motor skills or dexterity, slowness in movement execution associated with parkinsonian bradykinesia, or magnitude of tremor. Less obviously, some tools may be better suited than others for specific goals such as detecting subtle dysfunction early in disease, revealing aspects of brain function affected by disease, or tracking changes expected from treatment or disease progression. The purpose of this review is to describe and appraise selected measurement tools of fine motor skills appropriate for people with tremor disorders. In this context, we consider the tools' content-i.e., what movement features they focus on. In addition, we consider how measurement tools of fine motor skills relate to measures of a person's disease state or a person's function. These considerations affect how one should select and interpret the results of these tools in laboratory and clinical contexts.

Keywords: movement disorders, tremor, fine motor skills, dexterity, outcome measures, measurement

A reduction in upper extremity function and fine motor skills is a common consequence of living with a tremor disorder (Feys et al., 2002; Héroux et al., 2006; Dibble et al., 2010). Hand tremor, even when mild, causes difficulties with everyday tasks such as writing, self-care, and fine object manipulation. These activity limitations can lead to participation restrictions, social isolation, and a reduced quality of life (Diamond and Jankovic, 2005; BenitoLeon and Louis, 2006; Lorenz et al., 2006). Such consequences are made worse by embarrassment that often accompanies tremor (Bain et al., 1994; Louis and Rios, 2009). Although measuring tremor severity is important in clinical and research settings, it is just as important to measure the impact of tremor on fine motor skills and upper extremity function. Appropriate measurement of these constructs will ultimately influence patient care, intervention, and service prescription, as well as policy, and funding decisions (Hobart, 2003; Hobart et al., 2007). In the context of tremor disorders, clinicians, and researchers do not always measure activity limitations (Gorman et al., 1986; Sasso et al., 1991; Obwegeser et al., 2001; Vaillancourt et al., 2003; Fox et al., 2004; Van Der Walt et al., 2012), or they use tools with poor, unknown, or inadequate measurement properties for the targeted population (Herzog et al., 2003; Flora et al., 2010; Thevathasan et al., 2011; Ohye et al., 2012; Zappia et al., 2013).

The purpose of this mini-review is to (1) describe why clinicians and researchers should include measures of upper extremity function and fine motor skills in their evaluation of individuals with tremor disorders, (2) provide an overview of key measurement properties and attributes to be considered when selecting measurement tools, and (3) appraise and interpret several measures of fine motor skills that have been used in people with tremor disorders and consider other measures that may be useful. This mini-review does not represent an exhaustive review of available measurement tools. Rather, it is intended to focus on how measuring fine motor skills in people with tremor disorders can benefit from considering the wider literature about the development of scientifically sound clinical measures in general and hand function evaluation in particular.

\section{TREMOR DISORDERS AND ACTIVITY LIMITATIONS}

Movement disorders are a group of diseases and syndromes affecting a person's ability to produce and control movement, with tremor disorders being the most common (Deuschl et al., 1998). Most affected are the upper extremities, for example, the resting tremor of Parkinson's disease (PD), the action tremor that characterizes essential tremor (ET), or the intention tremor that develops following cerebellar damage [for a review see Deuschl et al. (2001)]. Functionally, tremor impacts the performance of fine motor skills such as feeding, drinking, writing, body care, and fine object manipulation (Feys et al., 2002; Héroux et al., 2006; Dibble et al., 2010), and results in activity limitation in 50-75\% of those living with upper extremity tremor from ET (Koller et al., 1986; Bain et al., 1994; Dogu et al., 2005).

An important part of evaluating individuals with tremor disorders is determining the type (e.g., rest, postural, kinetic, intention) and severity of tremor. Clinically this involves observing patients holding various postures and executing specified movements and assigning an ordinal scale rating. The use of accelerometers, digitizing tablets, and other technology can enable more precise 
measures of tremor severity (Elble et al., 1996, 2006; Norman et al., 2011). Clinical trials investigating the efficacy of pharmacological agents and neurosurgical techniques often focus on measures of tremor severity as their primary (or sole) outcome measure, especially in ET (e.g., Sasso et al., 1991; Obwegeser et al., 2001; Vaillancourt et al., 2003). The logic of this approach is evident: the intervention aims to reduce tremor amplitude. However, the ultimate therapeutic aim is to induce clinically meaningful improvements in functional performance and it should not be assumed that a reduction in tremor amplitude will result in a meaningful improvement in fine motor skills. Several studies have found weak or absent correlations between tremor amplitude and upper extremity function (Bain et al., 1993; Louis et al., 1999, 2001; Héroux et al., 2006), although this appears to depend on how tremor is measured (Norman et al., 2011). The lack of a strong relationship between a person's level of impairment and disability has been noted in other neurological and non-neurological conditions (O’Neill et al., 1998; Ploutz-Snyder et al., 2002; Hoang et al., 2012; Carvalho et al., 2013), and highlights the need to include measures of activity limitations.

In short, there is often a need to evaluate upper extremity function and fine motor skills in individuals with tremor disorders. Selecting an appropriate measurement tool is essential and should be founded on a clear understanding of the scientific quality of potential tools and their usefulness in the clinical setting (Finch et al., 2002; Hobart, 2003; Hobart et al., 2007).

\section{MEASUREMENT PROPERTIES AND CONSIDERATIONS}

Many guidance documents describe the criteria by which measurement tools should be evaluated (Finch et al., 2002; Revicki, 2007; Schoneveld et al., 2009; Baker et al., 2011) and funding agencies have published guidelines outlining the scientific requirements for patient-reported outcomes (PROs) and health-related quality of life (HR-QOL) measures (Scientific Advisory Committee of the Medical Outcome Trust (SAC MOT), 2002; United States Food and Drug Administration (USFDA), 2006). Despite their focus, these latter guidelines are pertinent to all measurement tools, including those of fine motor skills in people with tremor disorders.

A crucial first step in identifying and selecting an appropriate measurement tool is to define the purpose for which the measurement will be used. This helps clarify the reason for obtaining the measurement, identify the patient population being targeted, determine the setting in which the measurement tool will be used, and specify the aspect(s) of upper extremity fine motor skills that need(s) to be measured. Only when the measurement purpose has been clearly defined is it possible to properly evaluate and select the most appropriate measurement tool.

Table 1 presents key attributes that are used to describe the qualities and features of measurement tools (Baker et al., 2011; Finch et al., 2002; Scientific Advisory Committee of the Medical Outcome Trust (SAC MOT), 2002; United States Food and Drug Administration (USFDA), 2006). It includes a brief definition of each attribute and questions for consideration when selecting a tool to measure fine motor skills for people with tremor disorders. Table 1A presents attributes that apply to all measurement tools and includes several familiar terms, a few of which will be highlighted here. The conceptual and measurement model and scaling assumptions of a tool are closely related to validity. However, an explicit definition of the construct being measured is not always provided by the tool developers, or the definition describes the items of the tool rather than the construct it intends to measure. It is therefore important to ensure the measurement tool or one of its sub-scales focuses specifically on the construct of fine motor skills. Responsiveness is an important attribute when tracking disease progression or assessing the effectiveness of an intervention aimed at reducing tremor severity and improving hand function. For a tool to be responsive it must generate rigorous scientific measurements; unfortunately this is not always the case in measures of activity limitations (Hobart et al., 2007). When a measurement tool generates ordered scores, it may be assumed that increments in score are equivalent across the range of possible scores, i.e., that it is a linear measure. However, the nature of this relationship is often not known, which hampers the interpretation of scores. Modern psychometric methods such as Rasch analysis and Item Response Theory can improve a tool's properties and render them rigorous scientific measurements (Hambleton and Swaminathan, 1985; Andrich, 1988); the use of such methods is still not widespread in clinical research.

Fine motor skills encompass a wide range of simple and complex tasks with different functional and physiological requirements (McPhee, 1987; Wiesendanger and Serrien, 2001; Jones and Lederman, 2006; Kus et al., 2011). Table 1B presents attributes that are specific to measurement tools focused on fine motor skills. First, the scope of hand function assessed by a measurement tool should be considered. Measurement tools can focus on a single-concept task, a more complex task, or a series of tasks ranging in complexity. Next, upper extremity tremor is often asymmetrical (Farkas et al., 2006; Louis, 2010) and in some cases related to handedness (Machowska-Majchrzak et al., 2011; van der Hoorn et al., 2012). A detailed evaluation of fine motor skills in tremor disorders requires selecting measurement tools that assess unilateral tasks in the dominant and non-dominant hands as well as bilateral tasks (Héroux et al., 2006). In other contexts, it may be more relevant to focus on a single task done with one hand. Finally, task familiarity can influence a performance and self-reported function. Performance of tasks usually improves with practice (Wulf et al., 2010; Taylor and Ivry, 2012) and individuals with tremor often develop compensatory strategies such as stabilizing their upper extremity on a firm surface to successfully accomplish them (Sanes et al., 1990; Pascual-Leone et al., 1993). These factors will impact tracking individuals over time or comparing between groups.

\section{MEASURES OF FINE MOTOR SKILLS IN INDIVIDUALS WITH TREMOR}

Clinical measurement of people with tremor disorders has historically relied on disease-specific rating scales. In Table $2 \mathrm{~A}$, we show a selection of those tools that include components related to fine motor skills of the hands (reference citations for all measures discussed in this section can be found in Table 2.) All of these purport to measure impairment in functional tasks or specific movements that is likely to occur with a specific disease. With the exception of the PROs, the validity and reliability have generally only been proven with evaluators who are clinicians with some experience in movement disorders. These scales vary widely in the extent to 
Table 1 | Attributes of measurement tools.

\begin{tabular}{|c|c|c|}
\hline Attribute & Definition & $\begin{array}{l}\text { Questions when selecting a measurement tool for fine motor skills } \\
\text { in movement disorders involving tremor }\end{array}$ \\
\hline \multicolumn{3}{|c|}{ (A) ATTRIBUTES OF ALL MEASUREMENT TOOLS } \\
\hline $\begin{array}{l}\text { Conceptual and } \\
\text { measurement } \\
\text { model }\end{array}$ & $\begin{array}{l}\text { Rationale for and description of concepts and } \\
\text { populations a measure is intended to assess, } \\
\text { and in what populations }\end{array}$ & $\begin{array}{l}\text { Does the tool evaluate fine motor skills per se? Was it developed for a } \\
\text { particular patient population? Does it measure a broad construct, within which } \\
\text { fine motor skills are merely a component? Does it purport to represent the } \\
\text { progression of a specific disease? Or does it purport to represent impairment } \\
\text { or disability more generally? }\end{array}$ \\
\hline
\end{tabular}

Scaling

assumptions

Validity

Reliability

Responsiveness

Targeting

Data completeness/quality

Interpretability

Burden:

respondent and

administrative
Degree to which it is legitimate to sum scale or subscale scores, implying the sum reflects a common underlying construct

Degree to which instrument tools measures what it purports to measure, including content, construct, and criterion validity

Degree to which measure is free from random error, including test-retest and inter-rater reproducibility

Ability to detect change over time that is clinically relevant

Extent to which items of a tool are acceptable for the population under investigation

Degree to which all items of a tool can be obtained in each individual being evaluated

Degree to which one can assign meaning to a tool's quantitative scores

Time, effort, cost, personnel, or other demands required to complete the tool

\section{(B) ATTRIBUTES OF TOOLS TO MEASURE HAND FUNCTION}

Scope of hand function

Handedness and bilateral tasks

Relationship to learning or practice
Extent to which tasks or items adequately capture the construct of fine motor skills

Extent to which each hand is evaluated separately, and bilateral hand tasks are also evaluated

Extent to which the performance of tasks or items is influenced by whether they are familiar and well-practiced
Are the items in the scale or subscale related to a common underlying construct relevant to fine motor skills?

Do the tool's scores have known relationships to any other measures of fine motor skills?

Are scores consistent across raters and on separate occasions when patient status is thought to have remained stable?

Does the tool have sufficient responsiveness to indicate when a clinically meaningful change in fine motor skills has occurred? Is the minimal clinically important difference known for the population being investigated?

Is the tool targeted to a specific movement disorder involving tremor or is it generic, potentially applicable to people of various conditions? Also, are the scores from subjects with tremor likely to cluster near the bottom (floor) or top (ceiling) of the possible range of scores on the measure? See also scope of hand function, below

Is there a risk of missing data when the tool is used in subjects with movement disorders involving tremor?

Is the relationship between measurement tool scores and the continuum of the construct being measured linear? Are there established norms for age and/or gender in healthy subjects, movement disorders involving tremor, or other diseases?

Is it uncomfortable, frustrating, or embarrassing for subjects to answer the questions or do the tasks? What is the cost and portability of the instrument? Are there ongoing costs? How much experience is required by the evaluator to obtain valid and reliable scores in the population of interest?

Are the conceptual model, scaling assumptions, and targeting of the tool appropriate for the selected aspect of hand movement function? Is the task (or set of tasks) appropriately comprehensive with respect to hand dexterity for the population in whom one intends to use the tool?

Because tremor can affect right and left hands differently, does the tool adequately capture each hand's movement ability? If capturing natural function is important to the research or clinical question, does the tool include tasks that are normally done with two hands?

Are the tasks well-practiced for one hand, both hands, or neither? Have people learned compensatory strategies to perform tasks more quickly or smoothly? Is the familiarity and/or extent of compensation likely different between people? 
Table 2 | Selected measures related to hand dexterity.

\begin{tabular}{|c|c|c|c|}
\hline Name & Apparent construct & Burden & Focus on dexterity, \\
\hline
\end{tabular}

Measurement Interpretability

(A) SCALES DESIGNED EXPLICITLY FOR MOVEMENT DISORDERS

MDS-UPDRS part Reduction in ADL PRO; if patient is not

II (ADL) (Goetz

et al., 2008;

Martinez-Martin

et al., 2013)

MDS-UPDRS part
III (motor
examination) (see
citations above)

FTM scale part B

(Fahn et al., 1988)

TETRAS - ADL

subscale (Elble

et al., 2012)

TETRAS - perfor-

mance subscale

(see citation

above)
Impairment in

simple movements

that are typically

compromised in PD

Impairment in

simple movements

that are typically

compromised in ET
Experienced clinician, as above abilities, mostly self-care, that are typically compromised in ET
Experienced clinician must be available to rate the items, either by direct interaction or video observations

Experienced clinician, as above

clinician, as above

4-6 of 13 items rely on dexterity, depending how item is interpreted by each individual; handedness not considered, items performed with whatever hand is usual to rate)

3 of 18 items, plus hand tremor and rigidity evaluated in other items; both hands evaluated but entirely separately; no two-handed tasks included

11 of 12 items; handwriting is only with usual hand; drawing tasks done with each hand separately; some others are two-handed tasks
8-12 of 12 items, depending on how some items are interpreted; some tasks would typically be done with dominant hand, but scoring for some items includes the possibility of using both hands for stability; others would naturally be two-handed tasks

3 of 9 items; one handwriting task; two other tasks done separately with each hand; no two-handed tasks included

Ordinal scale ratings

Ordinal scal
ratings ras

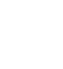


Table 2 | Continued

\begin{tabular}{|c|c|c|c|c|c|}
\hline Name & Apparent construct & Burden & $\begin{array}{l}\text { Focus on dexterity, } \\
\text { handedness and bilaterality }\end{array}$ & Measurement & Interpretability \\
\hline $\begin{array}{l}\text { SPDDS (Biemans } \\
\text { et al., 2001) }\end{array}$ & $\begin{array}{l}\text { Self-perception of } \\
\text { difficulty with a set } \\
\text { of tasks, mostly } \\
\text { self-care and } \\
\text { household }\end{array}$ & $\begin{array}{l}\mathrm{PRO} \text {; if patient is not } \\
\text { literate, a companion } \\
\text { can assist with } \\
\text { reading/ writing }\end{array}$ & $\begin{array}{l}\text { 13-16 of } 24 \text { items; most hand } \\
\text { tasks typically are done with } \\
\text { two hands, although one may } \\
\text { be supportive rather than } \\
\text { having fine motor control }\end{array}$ & $\begin{array}{l}\text { Ordinal scale } \\
\text { ratings }\end{array}$ & $\begin{array}{l}\text { Designed only for PD. No } \\
\text { population norms, other } \\
\text { than expectation of "able } \\
\text { to do alone without } \\
\text { difficulty" rating on all } \\
\text { items; Not systematically } \\
\text { used in any other } \\
\text { neurological or other } \\
\text { medical condition. Sum of } \\
\text { items interpretable as } \\
\text { lesser or greater evidence } \\
\text { of PD intruding on ADL, as } \\
\text { perceived by the person } \\
\text { him/herself }\end{array}$ \\
\hline $\begin{array}{l}\text { TDQ (Louis et al., } \\
\text { 2000) }\end{array}$ & $\begin{array}{l}\text { Self-perception of } \\
\text { difficulty with a set } \\
\text { of tasks, many } \\
\text { self-care, tasks are } \\
\text { likely familiar and } \\
\text { commonly } \\
\text { compromised by } \\
\text { tremor }\end{array}$ & $\begin{array}{l}\text { May be administered } \\
\text { by interview or } \\
\text { configured to be a } \\
\text { PRO }\end{array}$ & $\begin{array}{l}31 \text { of } 36 \text { items; most hand } \\
\text { tasks typically are done with } \\
\text { two hands, although one may } \\
\text { be supportive rather than } \\
\text { having fine motor control }\end{array}$ & $\begin{array}{l}\text { Ordinal scale } \\
\text { ratings }\end{array}$ & $\begin{array}{l}\text { Designed only for hand } \\
\text { tremor. No population } \\
\text { norms, other than } \\
\text { expectation of rating that } \\
\text { "tremor does not affect } \\
\text { the activity" on all items; } \\
\text { Not systematically used in } \\
\text { any other neurological or } \\
\text { other medical condition. } \\
\text { Sum of items } \\
\text { interpretable as lesser or } \\
\text { greater evidence of } \\
\text { tremor intruding on ADL, } \\
\text { as perceived by the } \\
\text { person him/herself }\end{array}$ \\
\hline \multicolumn{6}{|c|}{ (B) SCALES AND TOOLS DESIGNED FOR HAND FUNCTION } \\
\hline $\begin{array}{l}\text { ABILHAND } \\
\text { (Penta et al., } \\
\text { 1998) }\end{array}$ & $\begin{array}{l}\text { Self-perception of } \\
\text { manual ability in } \\
\text { daily activities }\end{array}$ & $\begin{array}{l}\mathrm{PRO} \text {; if patient is not } \\
\text { literate, a companion } \\
\text { can assist with } \\
\text { reading/ writing }\end{array}$ & $\begin{array}{l}23 \text { of } 23 \text { items; most hand } \\
\text { tasks typically are done with } \\
\text { two hands, although one may } \\
\text { be supportive rather than } \\
\text { having fine motor control }\end{array}$ & $\begin{array}{l}\text { Ordinal scale } \\
\text { ratings }\end{array}$ & $\begin{array}{l}\text { Designed for hand } \\
\text { function in people with } \\
\text { neurological or orthopedic } \\
\text { disorders. Results in a } \\
\text { person with tremor could } \\
\text { be compared to those } \\
\text { with stroke Mang et al., } \\
\text { 2011), CP (Arnould et al., } \\
\text { 2004), MS (Barrett et al., } \\
\text { 2012), systemic sclerosis, } \\
\text { and neuromuscular } \\
\text { disorders (Arnould et al., } \\
\text { 2012) }\end{array}$ \\
\hline $\begin{array}{l}\text { Action Research } \\
\text { Arm test (Lyle, } \\
\text { 1981) }\end{array}$ & $\begin{array}{l}\text { Grasp, grip, pinch, } \\
\text { and gross movement } \\
\text { of the upper limbs }\end{array}$ & $\begin{array}{l}\text { Evaluator needs no } \\
\text { clinical expertise, } \\
\text { needs only know the } \\
\text { tasks and scoring } \\
\text { criteria. Specific but } \\
\text { common items } \\
\text { required: balls, } \\
\text { blocks, etc. }\end{array}$ & $\begin{array}{l}\text { All } 19 \text { items reflect hand } \\
\text { function; } 16 \text { of } 19 \text { reflect fine } \\
\text { movement of hands or } \\
\text { fingers; both hands evaluated } \\
\text { but entirely separately; no } \\
\text { two-handed tasks included } \\
\text { except one screening task } \\
\text { (pouring) is two-handed }\end{array}$ & $\begin{array}{l}\text { Ordinal scale } \\
\text { ratings }\end{array}$ & $\begin{array}{l}\text { Designed for hand } \\
\text { function in people with } \\
\text { neurological disorders. } \\
\text { Results in a person with } \\
\text { tremor could be compared } \\
\text { to those with stroke (Platz } \\
\text { et al., 2005; Lin et al., } \\
2010 \text {; Baker et al., 2011; }\end{array}$ \\
\hline
\end{tabular}


Table 2 | Continued

\begin{tabular}{|c|c|c|c|c|c|}
\hline Name & Apparent construct & Burden & $\begin{array}{l}\text { Focus on dexterity, } \\
\text { handedness and bilaterality }\end{array}$ & Measurement & Interpretability \\
\hline & & & & & $\begin{array}{l}\text { Chen et al., 2012; Connell } \\
\text { and Tyson, 2012; Li et al., } \\
\text { 2012) }\end{array}$ \\
\hline $\begin{array}{l}\text { TEMPA } \\
\text { (Desrosiers et al., } \\
\text { 1995b) }\end{array}$ & $\begin{array}{l}\text { Time to complete } \\
\text { common hand } \\
\text { activities involving } \\
\text { grasp, grip, } \\
\text { transport, steady } \\
\text { hold, and release; } \\
\text { designed to capture } \\
\text { age-related changes }\end{array}$ & $\begin{array}{l}\text { Evaluator needs no } \\
\text { clinical expertise, } \\
\text { needs only know the } \\
\text { tasks and use } \\
\text { stopwatch. Specific } \\
\text { frame and items } \\
\text { required: e.g., } \\
\text { spoon, key, etc. }\end{array}$ & $\begin{array}{l}\text { Nine of nine items; four items } \\
\text { are one-hand tasks, evaluated } \\
\text { separately for each hand; five } \\
\text { items are two-handed tasks, } \\
\text { done according to individual } \\
\text { preference }\end{array}$ & $\begin{array}{l}\text { Time to } \\
\text { complete } \\
\text { tasks; ordinal } \\
\text { scale also } \\
\text { available if } \\
\text { person } \\
\text { cannot } \\
\text { complete a } \\
\text { task }\end{array}$ & $\begin{array}{l}\text { Published norms for } \\
\text { adults of various ages } \\
\text { (Desrosiers et al., 1995b; } \\
\text { Nedelec et al., 2011). } \\
\text { Results could also be } \\
\text { compared to those with } \\
\text { stroke (Higgins et al., } \\
\text { 2006; Platz et al., 2009), } \\
\text { ABI (Moseley and Yap, } \\
\text { 2003), MS (Feys et al., } \\
\text { 2007), and tremor (Héroux } \\
\text { et al., 2006) }\end{array}$ \\
\hline $\begin{array}{l}\text { Box and Block } \\
\text { test (Mathiowetz } \\
\text { et al., 1985a) }\end{array}$ & $\begin{array}{l}\text { Visuomotor control, } \\
\text { hand grasp, } \\
\text { transport, and } \\
\text { release, all at speed }\end{array}$ & $\begin{array}{l}\text { Evaluator needs only } \\
\text { know the task and } \\
\text { use a stopwatch. } \\
\text { Requires bins and } \\
100 \text { blocks }(2.5 \mathrm{~cm} \\
\text { cubes) }\end{array}$ & $\begin{array}{l}\text { One task: involves grasp, lift, } \\
\text { transport, and release of } \\
\text { blocks, performed } \\
\text { one-handed, each hand } \\
\text { evaluated separately }\end{array}$ & $\begin{array}{l}\text { Count of } \\
\text { blocks } \\
\text { moved }\end{array}$ & $\begin{array}{l}\text { Published norms for } \\
\text { adults of various ages } \\
\text { (Mathiowetz et al., 1985a; } \\
\text { Desrosiers et al., 1994). } \\
\text { Results could also be } \\
\text { compared to those with } \\
\text { stroke (Higgins et al., } \\
\text { 2006; Lin et al., 2010; } \\
\text { Connell and Tyson, 2012), } \\
\text { MS (Goodkin et al., 1998; } \\
\text { Platz et al., 2005; } \\
\text { Paltamaa et al., 2008), } \\
\text { ataxia (Corben et al., } \\
\text { 2010), and tremor (Héroux } \\
\text { et al., 2006) }\end{array}$ \\
\hline $\begin{array}{l}\text { Purdue pegboard } \\
\text { test (Tiffin and } \\
\text { Asher, 1948) }\end{array}$ & $\begin{array}{l}\text { Visuomotor control, } \\
\text { fingertip pinch, and } \\
\text { release }\end{array}$ & $\begin{array}{l}\text { Evaluator needs only } \\
\text { know the task and } \\
\text { use a stopwatch. } \\
\text { Requires specific } \\
\text { peg board and peg } \\
\text { items }\end{array}$ & $\begin{array}{l}\text { All tasks focus on control of } \\
\text { hand in space and fingertip } \\
\text { pinch and release; each hand } \\
\text { is evaluated separately, then } \\
\text { hands evaluated together in } \\
\text { parallel, and also in } \\
\text { two-handed assembly task }\end{array}$ & $\begin{array}{l}\text { Count of } \\
\text { pegs, or } \\
\text { count of } \\
\text { assembly } \\
\text { items in final } \\
\text { task }\end{array}$ & $\begin{array}{l}\text { Published norms for } \\
\text { adults of various ages } \\
\text { (Desrosiers et al., 1995a; } \\
\text { McCurry et al., 2001; } \\
\text { Onder et al., 2002, 2005). } \\
\text { Results could also be } \\
\text { compared to those with } \\
\text { PD (Adler et al., 2002; } \\
\text { Proud and Morris, 2010; } \\
\text { Postuma et al., 2012), } \\
\text { tremor (Héroux et al., } \\
\text { 2006; Sequeira et al., } \\
\text { 2012), and MS (Gallus and } \\
\text { Mathiowetz, 2003; } \\
\text { Thickbroom et al., 2005) }\end{array}$ \\
\hline $\begin{array}{l}\text { Nine Hole Peg } \\
\text { Test (Kellor et al., } \\
\text { 1971) }\end{array}$ & $\begin{array}{l}\text { Visuomotor control, } \\
\text { fingertip pinch, and } \\
\text { release }\end{array}$ & $\begin{array}{l}\text { Evaluator needs only } \\
\text { know the task and } \\
\text { use a stopwatch. } \\
\text { Requires specific } \\
\text { pegboard and pegs }\end{array}$ & $\begin{array}{l}\text { One task: involves grasp, lift, } \\
\text { transport, placing, and release } \\
\text { of pegs, performed } \\
\text { one-handed, each hand } \\
\text { evaluated separately }\end{array}$ & $\begin{array}{l}\text { Time to } \\
\text { complete } \\
\text { task }\end{array}$ & $\begin{array}{l}\text { Published norms for } \\
\text { adults of various ages } \\
\text { (Mathiowetz et al., 1985b; } \\
\text { Oxford Grice et al., 2003). } \\
\text { Results could also be }\end{array}$ \\
\hline
\end{tabular}


Table 2 | Continued

\begin{tabular}{|c|c|c|c|}
\hline Name & Apparent construct & Burden & $\begin{array}{l}\text { Focus on dexterity, } \\
\text { handedness and bilaterality }\end{array}$ \\
\hline
\end{tabular}

Measurement Interpretability

\section{handedness and bilaterality}

\section{(C) SINGLE-CONCEPT TASKS}

Finger tapping

Spiral drawing

Precision grip and/or lift typically 10 s, a component of

Ability to tap one

finger rapidly in specific time period, psychomotor speed

Varies: may use specific-built device or use standard computer input equipment; alternatively, may use observation or video recording
Ability to perform smooth circular movement required to draw or trace an Archimedes spiral
Ability to perform precise gripping and/or lifting of a small object
Digitizing tablet and stylus needed; expertise needed in signal conditioning and spectral analysis; alternatively may use simple paper version

Technology needed to obtain force and kinematic measurements; expertise needed in signal conditioning and spectral analysis
Single task: drawing an Archimedes spiral with a stylus; possible to evaluate both hands, although rarely reported

Single task: tapping as fast as possible, typically only with index finger; each hand evaluated separately

Single task: involves gripping and lifting a small object held between fingertips; possible to evaluate both hands, although rarely reported; bilateral grip tasks rarely reported

compared to those with stroke (Higgins et al., 2006; Lin et al., 2010), PD (Haaxma et al., 2008, 2010; Earhart et al., 2011), MS (Goodkin et al., 1998; Feys et al., 2007; Kierkegaard et al., 2012; van Winsen et al., 2010), and ataxia (Corben et al., 2010)

Simplest is count of taps in $10 \mathrm{~s}$; different tasks and/or calculations possible
Depending on task used, results can be compared to published norms (McCurry et al., 2001; Jimenez-Jimenez et al. 2011). Tasks have been used in many populations with neurological disorders, including stroke (Gebhardt et al., 2008; Calautti et al., 2010), PD

(Adler et al., 2002;

Quencer et al., 2007; Haaxma et al., 2008, 2010; Yokoe et al., 2009; Kim et al., 2011), and ET (Jimenez-Jimenez et al., 2010)

Various, e.g.: Tasks have been used in peak spectral people with Parkinson's tremor disease (Pullman, 1998; velocity Saunders-Pullman et al., $(\mathrm{mm} / \mathrm{s})$ 2008), ET (Pullman, 1998; Haubenberger et al., 2011; Louis et al., 2012), MS (Feys et al., 2007), and Niemann-Pick disease (Hsu et al., 2009)

Various, e.g.: $\quad$ Measures from such tasks maximum have been shown to be grip force (N), significantly different in maximum acceleration $\left(\mathrm{mm} / \mathrm{s}^{2}\right)$ controls and people with stroke (McDonnell et al., 2006), PD (Fellows and Noth, 2004; Benice et al., 2007), ET (Stani et al., 2010), Huntington's disease (Rao et al., 2011), or MS (Reilmann et al., 2013) 
Table 2 | Continued

\begin{tabular}{|c|c|c|c|c|c|}
\hline Name & Apparent construct & Burden & $\begin{array}{l}\text { Focus on dexterity, } \\
\text { handedness and bilaterality }\end{array}$ & Measurement & Interpretability \\
\hline Coin rotation & $\begin{array}{l}\text { Ability to rotate a } \\
\text { coin in one hand, } \\
\text { typically using } \\
\text { thumb, index and } \\
\text { long fingers }\end{array}$ & $\begin{array}{l}\text { Varies; may use live } \\
\text { observation or } \\
\text { videorecording; coin } \\
\text { is typically a nickel } \\
\text { (mass } 5 \mathrm{~g} \text {, diameter } \\
21 \mathrm{~mm} \text { ) }\end{array}$ & $\begin{array}{l}\text { Single task: rotating a coin in } \\
\text { one hand; possible to } \\
\text { evaluate both hands, although } \\
\text { rarely reported }\end{array}$ & $\begin{array}{l}\text { Count of } 180^{\circ} \\
\text { or } 360^{\circ} \\
\text { rotations of } \\
\text { the coin in } \\
10 \text { s, or time } \\
\text { to perform } \\
20 \text { rotations }\end{array}$ & $\begin{array}{l}\text { Depending on the } \\
\text { measure used, there may } \\
\text { be published norms } \\
\text { (Mendoza et al., 2009). } \\
\text { Task has been used in } \\
\text { people with left or right } \\
\text { hemisphere damage } \\
\text { (Mendoza et al., 2009) and } \\
\text { PD (Quencer et al., 2007; } \\
\text { Gebhardt et al., 2008; Foki } \\
\text { et al., 2010; Lee et al., } \\
\text { 2010; Vanbellingen et al., } \\
\text { 2011) and MS (Kamm } \\
\text { et al., 2012) }\end{array}$ \\
\hline
\end{tabular}

MDS-UPDRS, Movement Disorder Society Unified Parkinson Disease Rating Scale; ADLs, activities of daily living; PD, Parkinson's disease; FTM, Fahn-Tolosa-Marín scale; TETRAS, Tremor Research Group EssentialTremor Rating Assessment Scale; ET, essential tremor; SPDDS, Self-assessment Parkinson's Disease Disability Scale;

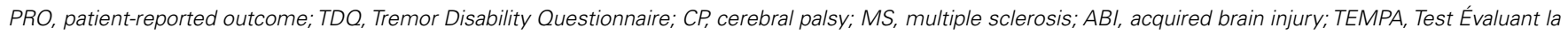
performance des Membres supérieurs des Personnes Âgées.

which their items capture hand function and whether dominant hand principally, both hands separately or both hands simultaneously. Nevertheless, it must be recognized that the underlying construct for each tool appears to be "extent of disease impact" and not necessarily a representation of the scope of typical activities any person, regardless of disease, would perform with the hands. The tools designed for PD have a lower proportion of items related to hand function than those designed for ET or other movement disorders: logical because PD generally impairs movement of many body parts, and bradykinesia is often a greater source of impairment than tremor. Although the newer of these scales have had some clinimetric properties thoroughly examined, they have not focused on interpretability beyond the target disease population.

In Table 2B, we list a selection of tools designed to measure hand function in ways that are useful for, but not specific to, neurological disorders. The ABILHAND is the only tool in this list that is a PRO. Although initially developed to capture hand disability in people with rheumatoid arthritis, it has since been used in people with stroke, multiple sclerosis, and neuromuscular disorders. Moreover, it was developed with more attention to measurement theory and rigorous testing than most tools in Table 2. As a result, its items are the most representative set of hand function tasks among the tools listed. Nevertheless, as a PRO, it captures what a patient prefers to do with either hand rather than systematically evaluating both right and left hands. The Action Research Arm Test (ARAT), originally developed for both rheumatological and neurological disorders, is best known as a measure of upper limb function used in patients with stroke. It is generic and has one of the lowest levels of burden among the tools having a multiitem approach to evaluating fine motor skills. The other four tools listed in Table 2B - the Test Évaluant la performance des Membres supérieurs des Personnes Âgées (TEMPA), the Box and Block
Test (BBT), and the two pegboard tasks - differ from the tools described above in two important ways. The first is that they are scored according to a physical value rather than an ordinal rating. The TEMPA and the Nine Hole Peg Test (NHPT) both have an outcome of time in seconds. The BBT and Purdue pegboard test both have an outcome of the number of objects moved in a set time period. The distinct advantage of tools with such outcomes is that intervals between scores are even and a ratio of two scores is valid: e.g., $20 \mathrm{~s}$ is twice as long as $10 \mathrm{~s}$ whereas an ordinal score of 4 would not necessarily represent twice as poor as a score of 2 . As a result, the tools with timing or counting may be better at contrasting two people's performances or tracking changes over time - i.e., they have better responsiveness. The second difference is that these tools all have published norms for adults of various ages. Tools with timing or counting outcomes are in contrast to ordinal scale systems in which individuals without disease are mostly presumed to be rated at the score indicating no evidence of disease or impairment (typically score 0 ). Tools with physical value outcomes thus assist clinicians and researchers to put an individual's results in the context of normal human variability, including age-associated changes - i.e., they have better interpretability for some contexts. Among this list, ABILHAND, ARAT, BBT, and NHPT are all highly recommended tools for people with stroke and other neurological conditions (Lin et al., 2010; Baker et al., 2011; Connell and Tyson, 2012) based on responsiveness, reliability, and validity. The BBT and NHPT have already been used in ET (see Table 2); the ABILHAND and ARAT may also have value in people with tremor disorders.

In Table 2C, we show a selection of fine motor skill measures that focus on a single task and may use technology to capture movement features. Like the tools in Table $2 \mathbf{B}$ with time units or counted objects as an outcome, these approaches result in scores 
that are physical values and generally have greater responsiveness and interpretability than ordinal scales. In contrast to those from Table 2B, however, these approaches do not attempt to reflect fine motor skills in multiple ways. Rather, they rely on a single task as informative about general dexterity. Finger-tapping and spiral-drawing both have a long history. For both tasks, the interpretability is increased by the availability of comparison data for healthy controls and other neurological populations. Precision grip-and-lift tasks generally have a high technology burden, but the outcomes have shown important differences between healthy controls and people with stroke, PD, ET, or Huntington's disease. Coin rotation is a relative newcomer in this category and its interpretability is growing as reports are published of its use in multiple populations. All four of these, and many other single-concept tasks, have the advantage of being simple ideas for a patient to understand and thus can be used in many populations. However, it is less plausible that single-concept tasks can validly represent the whole construct of fine motor skills (Hobart et al., 2007).

\section{SUMMARY AND RECOMMENDATIONS}

Measurement tools need to measure the constructs they intend to measure. They also need to be clinically meaningful and interpretable. In people with tremor disorders, however, no single measure of fine motor dexterity possesses all the attributes that would make it optimal for all research and clinical situations and with all patient populations. Each tool has advantages and disadvantages, and the importance of each is context-dependent. We recommend that researchers and clinicians consider the questions in Table 1 and ask themselves which attributes are most important for the tool(s) to be used in any context or project, and whether a single tool or a set of tools is most appropriate.

Patient care and research funding guidelines increasingly require the use of scientifically sound measures that capture all relevant aspects of patient status. In contexts where it is relevant to measure fine motor dexterity separately in both hands using a task that is quickly accomplished and allows comparison across patient populations, tools like coin rotation, finger tapping or

\section{REFERENCES}

Adler, C. H., Hentz, J. G., Joyce, J. N., Beach, T., and Caviness, J. N. (2002). Motor impairment in normal aging, clinically possible Parkinson's disease, and clinically probable Parkinson's disease: longitudinal evaluation of a cohort of prospective brain donors. Parkinsonism Relat. Disord. 9, 103-110.

Andrich, D. (1988). Rasch Models for Measurement. Beverly Hills: Sage.

Arnould, C., Penta, M., Renders, A., and Thonnard, J. L. (2004). ABILHANDKids: a measure of manual ability in children with cerebral palsy. Neurology 63, 1045-1052.

Arnould, C., Vandervelde, L., Batcho, C. S., Penta, M., and Thonnard, J. L. (2012). Can manual ability be measured with a generic ABILHAND scale? A cross-sectional study conducted on six diagnostic groups.
BMJ Open 2, doi:10.1136/bmjopen2012-001807

Bain, P. G., Findley, L. J., Thompson, P. D., Gresty, M. A., Rothwell, J. C., Harding, A. E., et al. (1994). A study of hereditary essential tremor. Brain 117, 805-824.

Bain, P. G., Mally, J., Gresty, M., and Findley, L. J. (1993). Assessing the impact of essential tremor on upper limb function. J. Neurol. 241, 54-61.

Baker, K., Cano, S. J., and Playford, E. D. (2011). Outcome measurement in stroke: a scale selection strategy. Stroke 42, 1787-1794.

Barrett, L., Cano, S., Zajicek, J., and Hobart, J. (2012). Can the ABILHAND handle manual ability in MS? Mult. Scler. doi:10.1177/1352458512462919

Benice, T. S., Lou, J. S., Eaton, R., and Nutt, J. (2007). Hand

peg tests would be most appropriate. In other contexts, it may be more relevant to capture the patient's perception of the dexterity limitations and be able to compare across patient populations, in which case the ABILHAND is the only one of our example tools that would suffice. In major research studies, when time, money, and other resources are invested to determine if a new treatment reduces hand tremor and improves dexterity, the measurements should reflect both these hypothesized benefits and a set of tools may be needed to capture a comprehensive picture of a treatment's benefits. For dexterity, this could include simple measures like coin rotation and the BBT, more complex measures like peg tests and the ARAT or TEMPA, and a measure of patient's perceived dexterity limitations such as the ABILHAND. If a choice exists, tools that generate interpretable, rigorous scientific measures should be favored.

Developing a new measurement tool is a large undertaking and requires considerable expertise and resources. Researchers are encouraged to consult with a health measurement specialist prior to starting and consider that it may be simpler to determine the measurement properties of an existing tool for a new application. In line with this idea, centers, and networks that are able to gather data from large cohorts of patients should consider investigating the attributes of existing tools, not only validity and reliability but also attributes like responsiveness and interpretability using modern psychometric methods such as Rasch analysis and Item Response Theory. At an individual level, clinicians and researchers can critically examine the tools used by their peers in the grants and manuscripts they review.

We hope that this mini-review serves to provide some guidance to clinicians and researchers who intend to measure fine motor skills in individuals with tremor disorders. Although we have attempted to provide current information, our selection of tools was intended to be illustrative rather than comprehensive. Moreover, even for the tools we selected, future research to reexamine these tools may show them to have different, perhaps better, attributes than we have concluded.

coordination as a quantitative measure of motor abnormality and therapeutic response in Parkinson's disease. Clin. Neurophysiol. 118, 1776-1784.

Benito-Leon, J., and Louis, E. D. (2006). Essential tremor: emerging views of a common disorder. Nat. Clin. Pract. Neurol. 2, 666-678.

Biemans, M. A., Dekker, J., and Woude, L. H. V. D. (2001). The internal consistency and validity of the self-assessment Parkinson's disease disability scale. Clin. Rehabil. 15, 221-228.

Calautti, C., Jones, P. S., Guincestre, J. Y., Naccarato, M., Sharma, N., Day, D. J., et al. (2010). The neural substrates of impaired finger tapping regularity after stroke. Neuroimage 50, 1-6.

Carvalho, C., Sunnerhagen, K. S., and Willen, C. (2013). Walking performance and muscle strength in the later stage post-stroke: a nonlinear relationship. Arch. Phys. Med. Rehabil. 94, 845-850.

Chen, H. F., Lin, K. C., Wu, C. Y., and Chen, C. L. (2012). Rasch validation and predictive validity of the action research arm test in patients receiving stroke rehabilitation. Arch. Phys. Med. Rehabil. 93, 1039-1045.

Connell, L. A., and Tyson, S. F. (2012). Clinical reality of measuring upper-limb ability in neurologic conditions: a systematic review. Arch. Phys. Med. Rehabil. 93, 221-228.

Corben, L. A., Tai, G., Wilson, C., Collins, V., Churchyard, A. J., and Delatycki, M. B. (2010). A comparison of three measures of upper limb function in Friedreich ataxia. J. Neurol. 257, 518-523. 
Desrosiers, J., Bravo, G., Hebert, R., Dutil, E., and Mercier, L. (1994). Validation of the box and block test as a measure of dexterity of elderly people: reliability, validity, and norms studies. Arch. Phys. Med. Rehabil. 75, 751-755.

Desrosiers, J., Hebert, R., Bravo, G., and Dutil, E. (1995a). The Purdue Pegboard Test: normative data for people aged 60 and over. Disabil. Rehabil. 17, 217-224.

Desrosiers, J., Hebert, R., Bravo, G., and Dutil, E. (1995b). Upper extremity performance test for the elderly (TEMPA): normative data and correlates with sensorimotor parameters. Test d'evaluation des membres supérieurs de personnes agées. Arch. Phys. Med. Rehabil. 76, 1125-1129.

Deuschl, G., Bain, P., Brin, M., and Ad hoc Scientific Committee (1998). Consensus statement of the Movement Disorder Society on Tremor. Mov. Disord. 13(Suppl. 3), 2-23.

Deuschl, G., Raethjen, J., Lindemann, M., and Krack, P. (2001). The pathophysiology of tremor. Muscle Nerve 24, 716-735.

Diamond, A., and Jankovic, J. (2005). The effect of deep brain stimulation on quality of life in movement disorders. J. Neurol. Neurosurg. Psychiatr. 76, 1188-1193.

Dibble, L. E., Cavanaugh, J. T., Earhart, G. M., Ellis, T. D., Ford, M. P., and Foreman, K. B. (2010). Charting the progression of disability in Parkinson disease: study protocol for a prospective longitudinal cohort study. BMC Neurol. 10:110. doi:10.1186/1471-2377-10-110

Dogu, O., Louis, E. D., Sevim, S., Kaleagasi, H., and Aral, M. (2005). Clinical characteristics of essential tremor in Mersin, Turkey A population-based door-to-door study. J. Neurol. 252, 570-574.

Earhart, G. M., Cavanaugh, J. T., Ellis, T., Ford, M. P., Foreman, K. B., and Dibble, L. (2011). The 9-hole PEG test of upper extremity function: average values, test-retest reliability, and factors contributing to performance in people with Parkinson disease. J. Neurol. Phys. Ther. 35, 157-163.

Elble, R., Comella, C., Fahn, S., Hallett, M., Jankovic, J., Juncos, J. L., et al. (2012). Reliability of a new scale for essential tremor. Mov. Disord. 27, 1567-1569.

Elble, R. J., Brilliant, M., Leffler, K., and Higgins, C. (1996). Quantification of essential tremor in writing and drawing. Mov. Disord. 11, 70-78.

Elble, R. J., Pullman, S. L., Matsumoto, J. Y., Raethjen, J., Deuschl, G., Tintner, R., et al. (2006). Tremor amplitude is logarithmically related to 4 - and 5-point tremor rating scales. Brain 129, 2660-2666.

Fahn, S., Tolosa, E., and Marin, C. (1988). "Clinical rating scale for tremor," in Parkinson's Disease and Movement Disorders, eds A. Jankovic, and E. Tolosa (Munich: Urban and Schwarzenberg), 225-234.

Farkas, Z., Csillik, A., Szirmai, I., and Kamondi, A. (2006). Asymmetry of tremor intensity and frequency in Parkinson's disease and essential tremor. Parkinsonism Relat. Disord. 12, 49-55.

Fellows, S. J., and Noth, J. (2004). Grip force abnormalities in de novo Parkinson's disease. Mov. Disord. 19, 560-565.

Feys, P., Duportail, M., Kos, D., Van Asch, P., and Ketelaer, P. (2002). Validity of the TEMPA for the measurement of upper limb function in multiple sclerosis. Clin. Rehabil. 16, 166-173.

Feys, P., Helsen, W., Prinsmel, A., Ilsbroukx, S., Wang, S., and Liu, X. (2007). Digitised spirography as an evaluation tool for intention tremor in multiple sclerosis. J. Neurosci. Methods 160, 309-316.

Finch, E., Brooks, D. J., Stratford, P., and Mayo, N. (2002). Physical Rehabilitation Outcomes Measures: A Guide to Enhanced Clinical Decision Making. Hamilton: BC Decker Inc.

Flora, E. D., Perera, C. L., Cameron, A. L., and Maddern, G. J. (2010). Deep brain stimulation for essential tremor: a systematic review. Mov. Disord. 25, 1550-1559.

Foki, T., Pirker, W., Klinger, N., Geissler, A., Rath, J., Steinkellner, T., et al. (2010). FMRI correlates of apraxia in Parkinson's disease patients OFF medication. Exp. Neurol. 225, 416-422.

Fox, P., Bain, P. G., Glickman, S., Carroll, C., and Zajicek, J. (2004). The effect of cannabis on tremor in patients with multiple sclerosis. Neurology 62, 1105-1109.

Gallus, J., and Mathiowetz, V. (2003). Test-retest reliability of the purdue pegboard for persons with multiple sclerosis. Am. J. Occup. Ther. 57, 108-111.

Gebhardt, A., Vanbellingen, T., Baronti, F., Kersten, B., and Bohlhalter, S. (2008). Poor dopaminergic response of impaired dexterity in Parkinson's disease: Bradykinesia or limb kinetic apraxia? Mov. Disord. 23, 1701-1706.

Goetz, C. G., Tilley, B. C., Shaftman, S. R., Stebbins, G. T., Fahn, S., Martinez-Martin, P., et al. (2008).
Movement Disorder Societysponsored revision of the Unified Parkinson's Disease Rating Scale (MDS-UPDRS): scale presentation and clinimetric testing results. Mov Disord. 23, 2129-2170.

Goodkin, D. E., Priore, R. L., Wende, K. E., Campion, M., Bourdette, D. N., Herndon, R. M., et al. (1998). Comparing the ability of various compositive outcomes to discriminate treatment effects in MS clinical trials. Mult. Scler. 4 480-486.

Gorman, W. P., Cooper, R., Pocock, P., and Campbell, M. J. (1986). A comparison of primidone, propranolol, and placebo in essential tremor, using quantitative analysis. J. Neurol. Neurosurg. Psychiatr. 49, 64-68.

Haaxma, C. A., Bloem, B. R., Borm, G. F., and Horstink, M. W. (2008). Comparison of a timed motor test battery to the Unified Parkinson's Disease Rating Scale-III in Parkinson's disease. Mov. Disord. 23 , 1707-1717.

Haaxma, C. A., Bloem, B. R., Overeem, S., Borm, G. F., and Horstink, M. W. (2010). Timed motor tests can detect subtle motor dysfunction in early Parkinson's disease. Mov. Disord. 25 1150-1156.

Hambleton, R. K., and Swaminathan, H. (1985). Item Response Theory: Principles and Applications. Boston: Klewer-Nijhoff.

Haubenberger, D., Kalowitz, D., Nahab, F. B., Toro, C., Ippolito, D., Luckenbaugh, D. A., et al. (2011). Validation of digital spiral analysis as outcome parameter for clinical trials in essential tremor. Mov. Disord. 26, 2073-2080.

Héroux, M. E., Parisi, S. L., LarocerieSalgado, J., and Norman, K. E (2006). Upper-extremity disability in essential tremor. Arch. Phys. Med. Rehabil. 87, 661-670.

Herzog, J., Volkmann, J., Krack, P., Kopper, F., Potter, M., Lorenz, D., et al. (2003). Two-year follow-up of subthalamic deep brain stimulation in Parkinson's disease. Mov. Disord. 18 1332-1337.

Higgins, J., Salbach, N. M., WoodDauphinee, S., Richards, C. L., Cote, R., and Mayo, N. E. (2006). The effect of a task-oriented intervention on arm function in people with stroke: a randomized controlled trial. Clin Rehabil. 20, 296-310.

Hoang, C. L. N., Salle, J., Mandigout, S., Hamonet, J., Macian-Montoro, F., and Daviet, J. (2012). Physical factors associated with fatigue after stroke: an exploratory study. Top. Stroke. Rehabil. 19, 369-376.
Hobart, J. (2003). Rating scales for neurologists. J. Neurol. Neurosurg. Psychiatr. 74(Suppl. 4), iv22-iv26.

Hobart, J. C., Cano, S. J., Zajicek, J. P., and Thompson, A. J. (2007). Rating scales as outcome measures for clinical trials in neurology: problems, solutions, and recommendations. Lancet Neurol. 6, 1094-1105.

Hsu, A. W., Piboolnurak, P. A., Floyd, A. G., Yu, Q. P., Wraith, J. E., Patterson, M. C., et al. (2009). Spiral analysis in Niemann-Pick disease type C. Mov. Disord. 24, 1984-1990.

Jimenez-Jimenez, F. J., Calleja, M. Alonso-Navarro, H., Rubio, L., Navacerrada, F., Pilo-de-la-Fuente, B., et al. (2011). Influence of age and gender in motor performance in healthy subjects. Neurol. Sci. 302, 72-80.

Jimenez-Jimenez, F. J., Rubio, L., Alonso-Navarro, H., Calleja, M., Pilo-de-la-Fuente, B., Plaza-Nieto, J. F., et al. (2010). Impairment of rapid repetitive finger movements and visual reaction time in patients with essential tremor. Eur. J. Neurol. 17, 152-159.

Jones, L. A., and Lederman, S. J. (2006). Human Hand Function. New York: Oxford University Press.

Kamm, C. P., Heldner, M. R., Vanbellingen, T., Mattle, H. P., Muri, R., and Bohlhalter, S. (2012). Limb apraxia in multiple sclerosis: prevalence and impact on manual dexterity and activities of daily living. Arch Phys. Med. Rehabil. 93, 1081-1085.

Kellor, M., Frost, J., Silberberg, N., Iversen, I., and Cummings, R. (1971). Hand strength and dexterity. Am. J. Occup. Ther. 25, 77-83.

Kierkegaard, M., Einarsson, U., Gottberg, K., Koch, L. V., and Holmqvist, L. W. (2012). The relationship between walking, manual dexterity, cognition and activity/participation in persons with multiple sclerosis. Mult. Scler. 18, 639-646.

Kim, J. W., Lee, J. H., Kwon, Y., Kim, C. S., Eom, G. M., Koh, S. B., et al. (2011). Quantification of bradykinesia during clinical finger taps using a gyrosensor in patients with Parkinson's disease. Med. Biol. Eng. Comput. 49, 365-371.

Koller, W., Biary, N., and Cone, S. (1986). Disability in essential tremor: effect of treatment. Neurology 36, 1001-1004.

Kus, S., van de Ven-Stevens, L. A. Coenen, M., Berno, S., Kollerits, B., and Cieza, A. (2011). What is our knowledge of functioning and disability in hand conditions based on? Arch. Phys. Med. Rehabil. 92, 1326-1332. 
Lee, M. S., Lyoo, C. H., Lee, M. J., Sim, J., Cho, H., and Choi, Y. H. (2010). Impaired finger dexterity in patients with parkinson's disease correlates with discriminative cutaneous sensory dysfunction. Mov. Disord. 25, 2531-2535.

Li, K. Y., Lin, K. C., Wang, T. N., Wu, C. Y., Huang, Y. H., and Ouyang, P. (2012). Ability of three motor measures to predict functional outcomes reported by stroke patients after rehabilitation. NeuroRehabilitation 30, 267-275.

Lin, K. C., Chuang, L. L., Wu, C. Y., Hsieh, Y. W., and Chang, W. Y. (2010). Responsiveness and validity of three dexterous function measures in stroke rehabilitation. J. Rehabil. Res. Dev. 47, 563-571.

Lorenz, D., Schwieger, D., Moises, H., and Deuschl, G. (2006). Quality of life and personality in essential tremor patients. Mov. Disord. 21, 1114-1118.

Louis, E. D. (2010). Essential tremor as a neuropsychiatric disorder. J. Neurol. Sci. 289, 144-148.

Louis, E. D., Barnes, L., Albert, S. M., Cote, L., Schneier, F. R., Pullman, S. L., et al. (2001). Correlates of functional disability in essential tremor. Mov. Disord. 16, 914-920.

Louis, E. D., Barnes, L. F., Wendt, K. J., Albert, S. M., Pullman, S. L., Yu, Q., et al. (2000). Validity and testretest reliability of a disability questionnaire for essential tremor. Mov. Disord. 15, 516-523.

Louis, E. D., Gillman, A., Boschung, S., Hess, C. W., Yu, Q., and Pullman, S. L. (2012). High width variability during spiral drawing: further evidence of cerebellar dysfunction in essential tremor. Cerebellum 11, 872-879.

Louis, E. D., and Rios, E. (2009). Embarrassment in essential tremor: prevalence, clinical correlates and therapeutic implications. Parkinsonism Relat. Disord. 15, 535-538.

Louis, E. D., Wendt, K. J., Albert, S. M., Pullman, S. L., Yu, Q., and Andrews, H. (1999). Validity of a performance-based test of function in essential tremor. Arch. Neurol. 56, 841-846.

Lyle, R. C. (1981). A performance test for assessment of upper limb function in physical rehabilitation treatment and research. Int. J. Rehabil. Res. 4, 483-492.

Machowska-Majchrzak, A., Pierzchala, K., Pietraszek, S., and Labuz-Roszak, B. (2011). Essential tremor - assessment of tremor accelerometric parameters' symmetry and the relationship between hand dominance and severity of tremor. Neurol. Neurochir. Pol. 45, 121-127.

Martinez-Martin, P., RodriguezBlazquez, C., Alvarez-Sanchez, M. Arakaki, T., Bergareche-Yarza, A., Chade, A., et al. (2013). Expanded and independent validation of the Movement Disorder SocietyUnified Parkinson's Disease Rating Scale (MDS-UPDRS). J. Neurol. 260, 228-236.

Mathiowetz, V., Volland, G., Kashman, N., and Weber, K. (1985a). Adult norms for the Box and Block Test of manual dexterity. Am. J. Occup. Ther. 39, 386-391.

Mathiowetz, V., Weber, K., Kashman, N., and Volland, G. (1985b). Adult norms for the Nine Hole Peg Test of finger dexterity. Occup Ther J Res 5, 24-38.

McCurry, S. M., Gibbons, L. E., Uomoto, J. M., Thompson, M. L., Graves, A. B., Edland, S. D., et al. (2001). Neuropsychological test performance in a cognitively intact sample of older Japanese American adults. Arch. Clin. Neuropsychol. 16, 447-459.

McDonnell, M. N., Hillier, S. L., Ridding, M. C., and Miles, T. S. (2006) Impairments in precision grip correlate with functional measures in adult hemiplegia. Clin. Neurophysiol. 117, 1474-1480.

McPhee, S. D. (1987). Functional hand evaluations: a review. Am. J. Occup. Ther. 41, 158-163.

Mendoza, J. E., Apostolos, G. T., Humphreys, J. D., Hanna-Pladdy, B., and O'Bryant, S. E. (2009). Coin rotation task (CRT): a new test of motor dexterity. Arch. Clin. Neuropsychol. 24, 287-292.

Moseley, A. M., and Yap, M. C. (2003). Interrater reliability of the TEMPA for the measurement of upper limb function in adults with traumatic brain injury. J. Head Trauma Rehabil. 18, 526-531.

Nedelec, B., Dion, K., Correa, J. A., and Desrosiers, J. (2011). Upper extremity performance test for the elderly (TEMPA): normative data for young adults. J. Hand Ther. 24, 31-42.

Norman, K. E., D'Amboise, S. N., Pari, G., and Héroux, M. E. (2011). Tremor during movement correlates well with disability in people with essential tremor. Mov. Disord. 26, 2088-2094.

Obwegeser, A. A., Uitti, R. J., Witte, R. J., Lucas, J. A., Turk, M. F., and Wharen, R. E. Jr. (2001). Quantitative and qualitative outcome measures after thalamic deep brain stimulation to treat disabling tremors. Neurosurgery 48, 274-281.
Ohye, C., Higuchi, Y., Shibazaki, T., Hashimoto, T., Koyama, T., Hirai, T., et al. (2012). Gamma knife thalamotomy for Parkinson disease and essential tremor: a prospective multicenter study. Neurosurgery 70, 526-535.

Onder, G., Penninx, B. W., Ferrucci, L., Fried, L. P., Guralnik, J. M., and Pahor, M. (2005). Measures of physical performance and risk for progressive and catastrophic disability: results from the Women's Health and Aging Study. J. Gerontol. A Biol. Sci. Med. Sci. 60, 74-79.

O'Neill, D. E., Gill-Body, K. M., and Krebs, D. E. (1998). Posturography changes do not predict functional performance changes. Am. J. Otol. 19, 797-803.

Onder, G., Penninx, B. W., Lapuerta, P., Fried, L. P., Ostir, G. V., Guralnik, J. M., et al. (2002). Change in physical performance over time in older women: the Women's Health and Aging Study. J. Gerontol. A Biol. Sci. Med. Sci. 57, M289-M293.

Oxford Grice, K., Vogel, K. A., Le, V., Mitchell, A., Muniz, S., and Vollmer, M. A. (2003). Adult norms for a commercially available Nine Hole Peg Test for finger dexterity. Am. J. Occup. Ther. 57, 570-573.

Paltamaa, J., Sarasoja, T., Leskinen, E., Wikstrom, J., and Malkia, E. (2008). Measuring deterioration in international classification of functioning domains of people with multiple sclerosis who are ambulatory. Phys Ther. 88, 176-190.

Pascual-Leone, A., Grafman, J., Clark, K., Stewart, M., Massaquoi, S., Lou, J. S., et al. (1993). Procedural learning in Parkinson's disease and cerebellar degeneration. Ann. Neurol. 34, 594-602.

Penta, M., Thonnard, J. L., and Tesio, L. (1998). ABILHAND: a Rasch-built measure of manual ability. Arch. Phys. Med. Rehabil. 79, 1038-1042.

Platz, T., Kaick, S. V., Mehrholz, J., Leidner, O., Eickhof, C., and Pohl, M. (2009). Best conventional therapy versus modular impairmentoriented training for arm paresis after stroke: a single-blind, multicenter randomized controlled trial. Neurorehabil. Neural. Repair 23, 706-716.

Platz, T., Pinkowski, C., Wijck, F. V., Kim, I. H., Bella, P. D., and Johnson, G. (2005). Reliability and validity of arm function assessment with standardized guidelines for the FuglMeyer Test, Action Research Arm Test and Box and Block Test: a multicentre study. Clin. Rehabil. 19 , 404-411.

Ploutz-Snyder, L., Manini, T., PloutzSnyder, R., and Wolf, D. (2002). Functionally relevant thresholds of quadriceps femoris strength. J. Gerontol. A Biol. Sci. Med. Sci. 57A, B144-B152.

Postuma, R. B., Lang, A. E., Gagnon, J. F., Pelletier, A., and Montplaisir, J. Y. (2012). How does parkinsonism start? Prodromal parkinsonism motor changes in idiopathic REM sleep behaviour disorder. Brain 135, 1860-1870.

Proud, E. L., and Morris, M. E. (2010). Skilled hand dexterity in Parkinson's disease: effects of adding a concurrent task. Arch. Phys. Med. Rehabil. 91, 794-799.

Pullman, S. L. (1998). Spiral analysis: a new technique for measuring tremor with a digitizing tablet. Mov. Disord. 13(Suppl. 3), 85-89.

Quencer, K., Okun, M. S., Crucian, G., Fernandez, H. H., Skidmore, F., and Heilman, K. M. (2007). Limbkinetic apraxia in Parkinson disease. Neurology 68, 150-151.

Rao, A. K., Gordon, A. M., and Marder, K. S. (2011). Coordination of fingertip forces during precision grip in premanifest Huntington's disease. Mov. Disord. 26, 862-869

Reilmann, R., Holtbernd, F., Bachmann, R., Mohammadi, S., Ringelstein, E. B., and Deppe, M. (2013). Grasping multiple sclerosis: do quantitative motor assessments provide a link between structure and function? J. Neurol. 260, 407-414.

Revicki, D. A. (2007). FDA draft guidance and health-outcomes research. Lancet 369, 540-542.

Sanes, J. N., Suner, S., and Donoghue, J. P. (1990). Dynamic organization of primary motor cortex output to target muscles in adult rats. I. Longterm patterns of reorganization following motor or mixed peripheral nerve lesions. Exp. Brain Res. 79, 479-491.

Sasso, E., Perucca, E., Fava, R., and Calzetti, S. (1991). Quantitative comparison of barbiturates in essential hand and head tremor. Mov. Disord. 6, 65-68.

Saunders-Pullman, R., Derby, C., Stanley, K., Floyd, A., Bressman, S., Lipton, R. B., et al. (2008). Validity of spiral analysis in early Parkinson's disease. Mov. Disord. 23, 531-537.

Schoneveld, K., Wittink, H., and Takken, T. (2009). Clinimetric evaluation of measurement tools used in hand therapy to assess activity and participation. J. Hand Ther. 22, 221-235. 
Scientific Advisory Committee of the Medical Outcome Trust. (2002). Assessing health status and qualityof-life instruments: attributes and review criteria. Qual. Life Res. 11, 193-205.

Sequeira, G., Keogh, J. W., and Kavanagh, J. J. (2012). Resistance training can improve fine manual dexterity in essential tremor patients: a preliminary study. Arch. Phys. Med. Rehabil. 93, 1466-1468.

Stani, T. M., Burchiel, K. J., Hart, M. J., Lenar, D. P., and Anderson, V. C. (2010). Effects of DBS on precision grip abnormalities in essential tremor. Exp. Brain Res. 201, 331-338.

Taylor, J. A., and Ivry, R. B. (2012). The role of strategies in motor learning. Ann. N. Y. Acad. Sci. 1251, 1-12.

Thevathasan, W., Schweder, P., Joint, C., Ray, N., Pretorius, P., Gregory, R., et al. (2011). Permanent tremor reduction during thalamic stimulation in multiple sclerosis. J. Neurol. Neurosurg. Psychiatr. 82, 419-422.

Thickbroom, G. W., Byrnes, M. L., Archer, S. A., Kermode, A. G., and Mastaglia, F. L. (2005). Corticomotor organisation and motor function in multiple sclerosis. J. Neurol. 252, 765-771.
Tiffin, J., and Asher, E. J. (1948). The Purdue pegboard; norms and studies of reliability and validity. J. Appl. Psychol. 32, 234-247.

United States Food and Drug Administration. (2006). Patient Reported Outcome Measures: Use in Medical Product Development to Support Labelling Claims. Available at: www.fda.gov/cber/gdlns/prolbl.pdf

Vaillancourt, D. E., Sturman, M. M., Verhagen Metman, L., Bakay, R. A., and Corcos, D. M. (2003). Deep brain stimulation of the VIM thalamic nucleus modifies several features of essential tremor. Neurology 61, 919-925.

van der Hoorn, A., Burger, H., Leenders, K. L., and de Jong, B. M. (2012). Handedness correlates with the dominant Parkinson side: a systematic review and meta-analysis. Mov. Disord. 27, 206-210.

Van Der Walt, A., Sung, S., Spelman, T., Marriott, M., Kolbe, S., Mitchell, P., et al. (2012). A double-blind, randomized, controlled study of botulinum toxin type A in MS-related tremor. Neurology 79, 92-99.

van Winsen, L. M., Kragt, J. J., Hoogervorst, E. L., Polman, C. H., and Uitdehaag, B. M. (2010). Outcome measurement in multiple sclerosis: detection of clinically relevant improvement. Mult. Scler. 16, 604-610.

Vanbellingen, T., Kersten, B., Bellion, M. Temperli, P., Baronti, F., Muri, R., et al. (2011). Impaired finger dexterity in Parkinson's disease is associated with praxis function. Brain Cogn. 77, 48-52.

Wang, Y. C., Magasi, S. R., Bohannon, R. W., Reuben, D. B., McCreath, H. E. Bubela, D. J., et al. (2011). Assessing dexterity function: a comparison of two alternatives for the NIH Toolbox. J. Hand Ther. 24, 313-320. Wiesendanger, M., and Serrien, D. J. (2001). Neurological problems affecting hand dexterity. Brain Res. Brain Res. Rev. 36, 161-168.

Wulf, G., Shea, C., and Lewthwaite, R. (2010). Motor skill learning and performance: a review of influential factors. Med. Educ. 44, 75-84.

Yokoe, M., Okuno, R., Hamasaki, T. Kurachi, Y., Akazawa, K., and Sakoda, S. (2009). Opening velocity, a novel parameter, for finger tapping test in patients with Parkinson's disease. Parkinsonism Rel. Disord. 15, 440-444.

Zappia, M., Albanese, A., Bruno, E., Colosimo, C., Filippini, G., Martinelli, P., et al. (2013).
Treatment of essential tremor: a systematic review of evidence and recommendations from the Italian Movement Disorders Association. J. Neurol. 260, 714-740.

Conflict of Interest Statement: The authors declare that the research was conducted in the absence of any commercial or financial relationships that could be construed as a potential conflict of interest.

Received: 25 February 2013; accepted: 24 April 2013; published online: 10 May 2013.

Citation: Norman KE and Héroux ME (2013) Measures of fine motor skills in people with tremor disorders: appraisal and interpretation. Front. Neurol. 4:50. doi: 10.3389/fneur.2013.00050

This article was submitted to Frontiers in Movement Disorders, a specialty of Frontiers in Neurology.

Copyright (C) 2013 Norman and Héroux. This is an open-access article distributed under the terms of the Creative Commons Attribution License, which permits use, distribution and reproduction in other forums, provided the original authors and source are credited and subject to any copyright notices concerning any third-party graphics etc. 